\title{
Noninvasive Ventilation in Prehospital Settings: A Narrative Review
}

\author{
Mohammed D. AlAhmari, Jithin K. Sreedharan \\ Department of Respiratory Care, Prince Sultan Military College of Health Sciences, Dammam, Saudi Arabia
}

\section{Abstract}

The prehospital use of noninvasive ventilation (NIV) by emergency medical services is increasing. Applying NIV in the prehospital setting began to gain more attention in the late 1990s when the primary form of noninvasive positive pressure ventilation emerged as a substitute to endotracheal intubation. For the last several years, NIV has become the standard of care for acute cardiogenic pulmonary edema and exacerbation of chronic obstructive pulmonary disease patients in the prehospital setting. A remarkable number of studies demonstrate a reduction in mortality and intubation rates in comparison to standard care when NIV is initiated in the prehospital setting, though there is a lack of evidence to strongly recommend the use of prehospital NIV as a first choice. An in-depth understanding of the science and technological background of NIV machines and interfaces can help attending clinicians in the prehospital setting and thus enhance therapeutic effectiveness by maximizing patient comfort, safety, and stability. Selections of the patients, devices, and interfaces, as well as achieving good patient-ventilator synchrony, are the key aspects of a successful outcome.

Keywords: Ambulance, interface, noninvasive ventilation, prehospital, respiratory failure

\section{INTRODUCTION}

Noninvasive ventilation (NIV) has proven to be an effective modality with different forms of acute respiratory failure (ARF), in particular, chronic obstructive pulmonary disease (COPD) and cardiogenic pulmonary edema (CPE) ${ }^{[1,2]}$ NIV as a modality delivers different forms of NIV support such as continuous positive airway pressure (CPAP) only or CPAP with pressure support, functions such as spontaneous breathing mode, and bi-level positive airway pressure, which mostly acts as an assisted breathing mode or controlled ventilation. ${ }^{[3,4]}$ NIV has shown to significantly improve vital signs, peripheral circulation, and arterial blood gases. $^{[3,5-7]}$ Therefore, early initiation of NIV is essential in ARF emergencies to avoid endotracheal intubation and to improve patient outcomes, ${ }^{[3,8,9]}$ particularly in prehospital settings. The efficacy of NIV is well established and robust in hospital settings with ARF of different etiologies. However, there is limited knowledge about NIV use in prehospital settings $;{ }^{[10,11]}$ in addition, there are inherent differences in emergency medical service (EMS) systems. ${ }^{[12]}$ This review will focus on the essentials of NIV practice in prehospital ambulance settings.

\begin{tabular}{|l|l|}
\hline \multicolumn{2}{|c|}{ Access this article online } \\
\hline Quick Response Code: & Website: \\
\hline & www.ijrconline.org \\
\hline & \\
\hline
\end{tabular}

\section{Physiology of Noninvasive Ventilation}

Pathophysiology of different etiologies of ARF includes an imbalance between an increased respiratory mechanical load and decreased respiratory muscle capacity, which results in reduced gas exchange, due to either intrapulmonary shunt or ventilation-perfusion mismatch, and cardiovascular function deterioration. ${ }^{[13]}$ The goal of NIV is to ensure the adequacy of lung gas exchange and normalize the increased load of work of breathing in diverse etiologies. NIV uniformly shows a reduction in inspiratory efforts when spontaneous breathing is assisted and hence reduces dyspnea. ${ }^{[14]}$ This substantial reduction in inspiratory efforts is evident by reduced diaphragmatic electromyography during NIV application. ${ }^{[15]}$ Respiratory mechanics are also improved with NIV. Application of inspiratory support alone would relief work of breathing by providing a greater proportion

Address for correspondence: Dr. Mohammed D. AlAhmari, Department of Respiratory Care, Prince Sultan Military College of Health Sciences, P.0. Box 33048, Dammam 31448, Saudi Arabia. E-mail:m.alahmari@psmchs.edu.sa

This is an open access journal, and articles are distributed under the terms of the Creative Commons Attribution-NonCommercial-ShareAlike 4.0 License, which allows others to remix, tweak, and build upon the work non-commercially, as long as appropriate credit is given and the new creations are licensed under the identical terms.

For reprints contact: reprints@medknow.com

How to cite this article: AlAhmari MD, Sreedharan JK. Noninvasive ventilation in prehospital settings: A narrative review. Indian J Respir Care 2020;9:20-5.

Received: $17-11-2019$

Accepted: 02-12-2019 Published: 08-01-2020 
of transpulmonary pressure during the inspiratory phase (the "push-pull" effect). ${ }^{[13]}$ Adding NIV will increase dynamic lung compliance by $17 \%-50 \%$ with a decrease in dynamic intrinsic positive end-expiratory pressure (PEEP) in diseased lung. ${ }^{[14]}$

Nasal CPAP and PEEP affect cardiovascular function. Evidence shows that nasal CPAP of more than $15-\mathrm{cm}_{2} \mathrm{O}$ in healthy participants reduces cardiac output by $20 \%-30 \%$ and reduces cardiac output by approximately $20 \%$ in patients with stable COPD. However, in congestive heart failure patients, NIV helps to decrease inspiratory efforts and left ventricular afterload and thus leads to increased cardiac output. ${ }^{[13,14]}$ Lung gas exchange is also improved by optimal settings of NIV. Such improvement is evident in blood gas values by increased $\mathrm{pH}$, improved $\mathrm{PaO}_{2}$, and decreased $\mathrm{PaCO}_{2}{ }^{[14]}$

Physiologically, NIV has been revealed to reduce respiratory workload and increase tidal volume, which improves dyspnea and pulmonary mechanics. However, at high levels of inspiratory support, it is important to pay attention to mask leak, and gastric insufflation may occur, which causes the failure of the NIV modality. ${ }^{[14]}$

\section{Effectiveness of Prehospital Noninvasive VentILATION}

\section{Noninvasive ventilation therapy in acute respiratory failure}

ARF is a complex condition, which could be a result of different pulmonary and nonpulmonary problems. ARF can be either hypoxemic or hypercapnic. ARF results in acute or acute-on-chronic respiratory acidosis and occurs because of respiratory muscle failure to meet adequate alveolar ventilation demands regardless of increased activity of the diaphragm. ${ }^{[16]}$

ARF is very common in prehospital medical services and a potential cause for life-threatening emergency that leads to increase of morbidity and mortality, as well as increased costs. ${ }^{[17]}$ In hypercapnic ARF in COPD particular patients in particular, NIV supports breathing to reduce the load placed on airways, ${ }^{[16]}$ whereas in ARF due to hypoxemia, such as CPE, NIV helps to prevent alveolar collapse and redistribution of intra-alveolar fluid, leading to improved lung compliance and reduced pressure load on breathing. ${ }^{[1]}$

NIV use in prehospital settings is still contradictory in terms of outcomes. Some studies show no benefit of NIV in prehospital contexts in regard to the rate of intubations, length of stay in intensive care units (ICUs), mortality, or hospital stay, ${ }^{[18]}$ whereas other studies showed a significant decrease in endotracheal intubation and mortality rates in patients of ARF using NIV modality. ${ }^{[11]}$

\section{Indications and contraindications of noninvasive ventilation}

The use of early NIV in ARF has shown a higher success rate. ${ }^{[8]} \mathrm{NIV}$ has been proven to be effective with exacerbated $\mathrm{COPD},{ }^{[19,20]} \mathrm{CPE},{ }^{[21]}$ and cardiac failure ${ }^{[22]}$ and can be used to support other etiologies with ARF. However, it showed poor evidence with severe acute respiratory distress syndrome. ${ }^{[23]}$ Table 1 summarizes the goals and indications of NIV in acute settings. ${ }^{[24]}$ In emergency seniors, endotracheal intubation and invasive ventilation must be initiated immediately. Perseverance with NIV application in these cases and undue delay in the application of invasive ventilation has been linked with increased mortality. ${ }^{[25]}$ Table 2 lists several absolute and relative contraindications of the use of NIV that may lead to invasive mechanical ventilation. ${ }^{[25,26]}$

\section{Noninvasive ventilation in ambulance care}

Prehospital care is normally delivered by ambulance services. Patients with ARF require proper prehospital management while transportation to hospital. The cause of ARF in these patients depends on the underlying causes, which is difficult to determine at this stage. Therefore, prehospital treatment usually follows a common pathway to treat ARF rather than a specific protocol, which usually happens in hospital settings. The risk of increased mortality in ARF patients increases significantly with distance traveled in an ambulance to the hospital from $10 \%$ at $<10-\mathrm{km}$ distances versus $20 \%$ at $>20$-km distances. ${ }^{[27]}$ This mortality rate can be explained by the unavailability of respiratory support as prehospital treatment for patients with acute hypoxemic respiratory failure $(\mathrm{RF})$ in particular.

Prehospital NIV practice has been studied in many studies, with the outcomes suggesting reduced mortality and rate of intubations, but these studies have limitations, including small

Table 1: Goals and indications of NIV in acute settings

Goal of NIV application in acute care

Improve patients' comfort

Relieve symptoms

Decrease work of breathing

Improve lung gas exchange

Avoid intubation

Decrease length of hospital stay

\begin{tabular}{l}
\hline \multicolumn{1}{c}{ Acute indications of NIV application } \\
\hline Exacerbated COPD patients \\
Acute cardiogenic pulmonary edema \\
Postoperative respiratory failure \\
Difficult weaning \\
Respiratory infection in immunocompromised state \\
Hypoxemic respiratory failure
\end{tabular}

COPD: Chronic obstructive pulmonary disease

Table 2: Absolute and relative contraindications of NIV Relative

Facial deformity

Poor cough reflex

Confusion

Moderate bulbar weakness

Unstable angina/Myocardial infarction

Esophageal or gastric surgery (recent) 
AlAhmari and Sreedharan: NIV and pre-hospital setting

\begin{tabular}{|c|c|c|c|}
\hline Device Type & Advantage & Disadvantage & Products in the market \\
\hline $\begin{array}{l}\text { Valved CPAP Systems } \\
\text { Threshold resistors } \\
\text { Weighted-ball } \\
\text { Spring-loaded }\end{array}$ & $\begin{array}{l}\text { Economical and Easy to use } \\
\text { Acceptable range of pressure and } \mathrm{FiO}_{2} \text { Delivery. } \\
\text { Pressure delivered is not affected by the flow } \\
\text { changes in the system (Sigh/Cough) } \\
\text { Gas consumption is low }\end{array}$ & $\begin{array}{l}\text { Gravity dependant } \\
\text { Restricted patient movement } \\
\text { No Alram or monitoring } \\
\text { Noisy }\end{array}$ & $\begin{array}{l}\text { Pulmodyme O2 Max } \\
\text { Pulmodyme GO-PAP }\end{array}$ \\
\hline $\begin{array}{l}\text { Continuous flow } \\
\text { generators }\end{array}$ & $\begin{array}{l}\text { Easy to use } \\
\text { Fixed \& variable flow adjustment is possible. } \\
\text { All in one knob pressure/ } \mathrm{O}_{2} \text { level adjustment } \\
\text { WOB is reduced due to high peak flow rates }\end{array}$ & $\begin{array}{l}\text { Pressure delivered is affected by } \\
\text { changes in flow through the system. } \\
\mathrm{FIO}_{2} \text { and pressures delivered are } \\
\text { flow dependent. } \\
\text { Consumption of gas is high, it } \\
\text { varies from 30LPM-100LPM }\end{array}$ & $\begin{array}{l}\text { Respironics Whisperflow } \\
\text { Vital Signs-Downs fixed and } \\
\text { adjustable flow generators } \\
\text { Emergent Respiratory-Port } \mathrm{O}_{2} \text { Vent } \\
\text { The Boussignac CPAP - Vygon }\end{array}$ \\
\hline $\begin{array}{l}\text { Portable } \\
\text { Demand-Flow devices }\end{array}$ & $\begin{array}{l}\text { Demand flow system delivers CPAP without } \\
\text { wasting oxygen. } \\
\text { No batteries required }\end{array}$ & $\begin{array}{l}\text { WOB is comparatively high. } \\
\text { Monitoring of the Patient Device } \\
\text { interaction is limited }\end{array}$ & $\begin{array}{l}\text { MACS CPAP - Airon } \\
\text { Emergent Respiratory-PortO2Vent }\end{array}$ \\
\hline $\begin{array}{l}\text { Mechanical ventilators } \\
\text { for Pre-hospital } \\
\text { NIV (Portable, } \\
\text { noninvasive, } \\
\text { and critical care } \\
\text { ventilators.) }\end{array}$ & $\begin{array}{l}\text { Precise oxygen delivery } \\
\text { Enhanced patient safety and comfort. } \\
\text { Better flow delivery } \\
\text { Demand systems to reduce the WOB. } \\
\text { Quantify and compensate leaks } \\
\text { Patient-monitoring. } \\
\text { Alarms for disconnection, System failure. } \\
\text { Option to switch to assisted Ventilation. } \\
\text { Turbine Operated. } \\
\text { Adjustable inspiratory Flow. } \\
\text { Back up ventilation }\end{array}$ & $\begin{array}{l}\text { Long triggering delay. } \\
\text { Less responsive } \\
\text { Trigger sensitivity. } \\
\text { Risk of rebreathing when there is } \\
\text { no adequate flow to facilitate the } \\
\text { intentional leak. } \\
\text { Flow dependent Expiratory Cycling. } \\
\text { No guaranteed VT. } \\
\text { Pressure generation varies. } \\
\text { Need expertise to operate. } \\
\text { Weight varies from } 2.5 \mathrm{kgs} \text { to } 27 \mathrm{kgs} \\
\text { Variable oxygen delivery in the } \\
\text { absence of blenders. }\end{array}$ & $\begin{array}{l}\text { Philips Respironics BiPAP S/T, } \\
\text { Trilogy } 100 . \\
\text { Resmed Inc. Stellar/Astral/Elisee } \\
\text { Series. } \\
\text { Draeger Oxylog3000/Carina } \\
\text { Hamilton MR1 } \\
\text { Maquet Inc. Servo Air } \\
\text { Medtronic.Inc Newport ht70Plus }\end{array}$ \\
\hline
\end{tabular}

CPAP: Continuous positive airway pressure, NIV: Noninvasive ventilation, WOB: Work of Breathing, LPM: Liter per minute, VT: Tidal Volume, BiPAP: Bilevel positive airway pressure, S/T: Spontaneous Time

sample size and inconsistent findings. ${ }^{[28]}$ During prehospital NIV application and hospital transfer, it is important to remember that the EMS or paramedics are away from the inhospital critical care services and support in case of deterioration. In addition, the NIV equipment may be limited by space inside the ambulance during transfer. These factors may play a role in the certainty of NIV effectiveness in prehospital settings.

Prehospital NIV can reduce the rate of mortality if used earlier in the ambulance as opposed to waiting until arrival at the hospital. ${ }^{[28]}$ Hubble et al. ${ }^{[29]}$ showed in their study that around 4/1000 patients were eligible to be transported by ambulance services for NIV treatment. Garuti et al. also reported in a prehospital setting that when helmet NIV interfaces were used by a trained nurse, the mortality rate was reduced by $94 \%$. ${ }^{[30]}$ This suggests that prehospital NIV can be effective with certain cases only if ambulances are technically equipped and EMS or paramedics are well trained on this modality. One crucial factor to address is that NIV success is associated with early initiation during the deterioration of $\mathrm{RF}^{\left[{ }^{[3]}\right.}$

\section{Technology and Equipment for Prehospital Noninvasive Ventilation}

A diverse range of equipment is available for establishing NIV in prehospital transport. Each has its own discrepancies in performance and topography. They range from disposable devices to fully loaded transport ventilators with NIV capabilities. Clinicians must have a thorough understanding of the functions and settings to meet the operational necessities. The earlier devices had many limitations with regard to the power backup/battery life, type and source of gas supply, lack of suitable modes, oxygen source, etc., whereas the latest generation of devices offers a wide range of opportunities, including but not limited to switching the patients from NIV to invasive modes without changing the device and connections. ${ }^{[32-34]}$

\section{Ideal Devices for Prehospital Noninvasive VENTILATION}

All lightweight, compact, durable, and easy-to-navigate devices are ideal for prehospital NIV, especially during transport. Turbine-driven NIV machines have the advantage of being free from compressed air, lightweight, and hold back the space. However, some modern machines have the option to switch between compressed air and turbine settings. ${ }^{[35]}$ An interchangeable battery with a good operating time can prolong the use of NIV without complications. When used in the prehospital and transport settings, NIV machines need to be secured well to avoid issues associated with sudden movement such as disconnection or inadvertent falls. It is 
AlAhmari and Sreedharan: NIV and pre-hospital setting

\begin{tabular}{|c|c|c|}
\hline Device & Benefits & Drawbacks \\
\hline \multirow{6}{*}{$\begin{array}{l}\text { Nasal } \\
\text { mask }\end{array}$} & \multirow{4}{*}{$\begin{array}{l}\text { Minimal danger of } \\
\text { aspiration } \\
\text { Lesser claustrophobia } \\
\text { Aid to communicate, eat } \\
\text { \& expectorate }\end{array}$} & Mouth leak \\
\hline & & \multirow{2}{*}{$\begin{array}{l}\text { Higher resistance through nasal } \\
\text { passages }\end{array}$} \\
\hline & & \\
\hline & & $\begin{array}{l}\text { Less effective with nasal } \\
\text { obstruction }\end{array}$ \\
\hline & Easy to tailor and secure & Nasal irritation and rhinorrhea \\
\hline & Less dead space & Mouth dryness \\
\hline \multirow{4}{*}{$\begin{array}{l}\text { Oronasal } \\
\text { mask }\end{array}$} & Better oral leak control & Greater dead space \\
\hline & \multirow{3}{*}{$\begin{array}{l}\text { More effective in } \\
\text { mouth-breathers }\end{array}$} & Claustrophobia \\
\hline & & $\begin{array}{l}\text { Greater risk of aspiration \& } \\
\text { Asphyxiation }\end{array}$ \\
\hline & & Difficult to speak \\
\hline \multirow{3}{*}{$\begin{array}{l}\text { Total } \\
\text { face } \\
\text { mask }\end{array}$} & \multirow{3}{*}{$\begin{array}{l}\text { One size fits all \& Easy } \\
\text { to fit } \\
\text { Less risk of facial skin } \\
\text { breakdown }\end{array}$} & Potential for drying of the eyes \\
\hline & & Cannot deliver aerosol \\
\hline & & Potentially more dead space \\
\hline
\end{tabular}

preferred to have an attachable support to hook to the bed or a wall-mounted stand with a charging station for the machine. A sophisticated leak compensation feature improves triggering and eliminates asynchrony, especially during the initial phase of application, which is crucial for establishing tolerance. ${ }^{[2]} \mathrm{A}$ highly visible and audible alarm profile with quick feedback helps the clinician to diagnose and treat adverse events such as disconnections, excessive leaks, and life-threatening apneas.

Table 3 summarizes the most commonly used devices as well as their advantages and disadvantages. ${ }^{[36-39]}$

\section{Interface Selection for the Prehospital Noninvasive Ventilation}

Important factors in selecting the right interface are type of RF, patient condition, and tolerance. Precautionary measures must be taken in order to avoid asphyxia/carbon dioxide narcosis as a result of ventilator failure or disconnection before choosing the interface. Choice of interface also depends on the type of machine circuits used. The need for anti-asphyxia valves (i.e., vented or nonvented masks) depends on the type of circuit. Respiratory therapists and attending personnel must be responsive to this imperative difference between ventilators. ${ }^{[40,41]}$ Frequently used interfaces and their advantages and disadvantages are listed in Table 4. Regardless of the device used and patient condition, however, a well-fitting interface is an indispensable part of successful NIV in prehospital care. ${ }^{[12]}$

\section{Clinical Outcomes of Prehospital Noninvasive VeNTILATION}

Studies examining the impact of prehospital NIV use have yielded inconsistent outcomes. Although there is a consensus that the use of prehospital NIV, mainly CPAP, improves vital signs in patients with ARF with an inclination toward the rate of intubation, the impact on mortality is unclear. Mal et al., in their systematic review and meta-analysis of randomized controlled trials (RCTs) on prehospital CPAP/NIV, correlated a decrease in requirement for inhospital invasive ventilation and mortality when prehospital noninvasive positive pressure ventilation was initiated. ${ }^{[42]}$ This review included only just randomized and controlled studies, where seven heterogeneous studies on both CPAP and NIV, with a total of 632 patients, were pooled in a meta-analysis. This revision comprised primarily 361 studies, which was then developed based on exclusion criteria to seven RCTs, which were thought to have a relatively small risk of bias.

Another review by Simpson and Bendall stated that prehospital CPAP/NIV seems to be a prudent and viable therapy that marks quick progress in physiological status and that it may possibly help to reduce the requirement for intubation related to late management in the emergency care department. ${ }^{[43]}$ They also found that there is a paucity of evidence that NIV might reduce mortality.

Simpson and Bendall documented diverse methods of NIV but did not distinguish among them. Bakke et al., in their systemic review of controlled studies on the use of CPAP and NIV in prehospital treatment of patients with ARF, found an increasingly exponential trend toward a reduction of intubation rate, but there is a scarcity of evidence to strongly recommend the use of prehospital NIV. ${ }^{[3]}$ Hensel et al., in their prospective observational study steered in a prehospital setting to examine the usefulness of NIV used in patients with COPD exacerbation or CPE with particular reference to the impact of the extent of prehospital NIV treatment, found a significant improvement in the physiological values in NIV groups compared to the historical controlled group ${ }^{[44]}$ They also found that the patients with COPD exacerbation and CPE benefited significantly irrespective of the distance between the scene of emergency and the emergency and the nearest emergency department or hospital.

\section{Essentials for Noninvasive Ventilation Success Personnel and training}

Initiating NIV in prehospital settings is time-consuming and requires close monitoring and attention, and staff expertise for adequate adaptation and success management and treatment. Therefore, continuous staff training has shown to diminish time and patient-to-staff ratio. ${ }^{[45]}$ Proper training is an important goal for better NIV outcomes in prehospital settings. ${ }^{[45]}$ Expertise in NIV by maintaining proper training and accumulative experience over time, especially in acute RF, is essential for successful treatment ${ }^{[46]}$ and also contributes to an improved clinical practice and better prognosis if applied earlier. ${ }^{[47]}$ During transportation, an experienced staff member who is well trained in airway management and cardiopulmonary resuscitation should accompany patients on NIV. ${ }^{[48]}$ In addition, it is essential that the personnel involved during transportation are skilled and confident in NIV application and knowledgeable 
AlAhmari and Sreedharan: NIV and pre-hospital setting

in type of ventilators, accessories, and different interfaces with NIV use. ${ }^{[49]}$

Preparation, education, and coaching from health-care providers are essential for patients to become comfortable and use the NIV device. In an acute respiratory distress situation, the prehospital care provider will need to act fast and assemble the NIV device quickly in order to avoid further deterioration that requires invasive intubation. Anxious or agitated patients in emergencies need proper management so that they do not fight the machine or become claustrophobic from the full mask. Proper preparation during prehospital care includes careful handling of the connection between the NIV and filled oxygen sources. Initial action includes applying the mask to the patient's face with coaching while taking in deep breaths. Once the patient can accept and tolerate the interface, then the head strap can be applied. Continuous assessment for patient respiratory function status is important for the success of NIV application in prehospital settings. ${ }^{[50]}$

\section{Conclusion}

NIV is beneficial to selected patients in the form of shorter ICU stays, reduced mortality, and intubation rates when applied in the prehospital setting. By stipulating that NIV treatment is provided by a proficient emergency crew, a negligible amount of additional time is needed to apply NIV. With technology advancements, implementation of care plans/protocols, and extensive training of resource personnel, CPAP deemed to be the first choice of intervention, since it is inexpensive and easy to execute in clinical routine. However, this issue demands more research, and larger RCTs are essential to consolidate an evidence base for NIV use in prehospital settings.

\section{Financial support and sponsorship}

Nil.

\section{Conflicts of interest}

There are no conflicts of interest.

\section{RefEREnCES}

1. Ram FS, Picot J, Lightowler J, Wedzicha JA. Non-invasive positive pressure ventilation for treatment of respiratory failure due to exacerbations of chronic obstructive pulmonary disease. Cochrane Database Syst Rev 2004;1:CD004104.

2. Li H, Hu C, Xia J, Li X, Wei H, Zeng X, et al. A comparison of bilevel and continuous positive airway pressure noninvasive ventilation in acute cardiogenic pulmonary edema. Am J Emerg Med 2013;31:1322-7.

3. Bakke SA, Botker MT, Riddervold IS, Kirkegaard H, Christensen EF. Continuous positive airway pressure and noninvasive ventilation in prehospital treatment of patients with acute respiratory failure: A systematic review of controlled studies. Scand J Trauma Resusc Emerg Med 2014;22:69.

4. Hörmann C, Baum M, Putensen C, Mutz NJ, Benzer H. Biphasic positive airway pressure (BIPAP)-a new mode of ventilatory support. Eur J Anaesthesiol 1994;11:37-42.

5. Joshi N, Estes MK, Shipley K, Lee HD, Zaurova M. Noninvasive ventilation for patients in acute respiratory distress: An update [digest]. Emerg Med Pract 2017;19:S1-2.

6. Nielsen VM, Madsen J, Aasen A, Toft-Petersen AP, Lübcke K, Rasmussen BS, et al. Prehospital treatment with continuous positive airway pressure in patients with acute respiratory failure: A regional observational study. Scand J Trauma Resusc Emerg Med 2016;24:121.

7. Schmidbauer W, Ahlers O, Spies C, Dreyer A, Mager G, Kerner T. Early prehospital use of non-invasive ventilation improves acute respiratory failure in acute exacerbation of chronic obstructive pulmonary disease. Emerg Med J 2011;28:626-7.

8. Celikel T, Sungur M, Ceyhan B, Karakurt S. Comparison of noninvasive positive pressure ventilation with standard medical therapy in hypercapnic acute respiratory failure. Chest 1998;114:1636-42.

9. Plant PK, Owen JL, Elliott MW. Early use of non-invasive ventilation for acute exacerbations of chronic obstructive pulmonary disease on general respiratory wards: A multicentre randomised controlled trial. Lancet 2000;355:1931-5.

10. Willmore A, Dionne R, Maloney J, Ouston E, Stiell I. Effectiveness and safety of a prehospital program of continuous positive airway pressure (CPAP) in an urban setting. CJEM 2015;17:609-16.

11. AlAhmari MD, Al-Otaibi H, Qutub H, AlBalawi I, Alqahtani A, Almasoudi B. Noninvasive ventilation utilization in the Kingdom of Saudi Arabia: Results of a national survey. Ann Thorac Med 2018;13:237-42.

12. Williams TA, Finn J, Perkins GD, Jacobs IG. Prehospital continuous positive airway pressure for acute respiratory failure: A systematic review and meta-analysis. Prehosp Emerg Care 2013;17:261-73.

13. Peñuelas O, Frutos-Vivar F, Esteban A. Noninvasive positive-pressure ventilation in acute respiratory failure. CMAJ 2007;177:1211-8.

14. Kallet RH, Diaz JV. The physiologic effects of noninvasive ventilation. Respir Care 2009;54:102-15.

15. Polese G, Vitacca M, Bianchi L, Rossi A, Ambrosino N. Nasal proportional assist ventilation unloads the inspiratory muscles of stable patients with hypercapnia due to COPD. Eur Respir J 2000;16:491-8.

16. Brochard L, Isabey D, Piquet J, Amaro P, Mancebo J, Messadi AA, et al. Reversal of acute exacerbations of chronic obstructive lung disease by inspiratory assistance with a face mask. N Engl J Med 1990;323:1523-30.

17. Krum H, Abraham WT. Heart failure. Lancet 2009;373:941-55.

18. Aguilar SA, Lee J, Dunford JV, Castillo E, Lam B, Choy J, et al. Assessment of the addition of prehospital continuous positive airway pressure (CPAP) to an urban emergency medical services (EMS) system in persons with severe respiratory distress. J Emerg Med 2013;45:210-9.

19. Brochard L, Mancebo J, Wysocki M, Lofaso F, Conti G, Rauss A, et al. Noninvasive ventilation for acute exacerbations of chronic obstructive pulmonary disease. New Engl J Med 1995;333:817-22.

20. Kramer N, Meyer TJ, Meharg J, Cece RD, Hill NS. Randomized, prospective trial of noninvasive positive pressure ventilation in acute respiratory failure. Am J Respir Crit Care Med 1995;151:1799-806.

21. Mehta S, Jay GD, Woolard RH, Hipona RA, Connolly EM, Cimini DM, et al. Randomized, prospective trial of bilevel versus continuous positive airway pressure in acute pulmonary edema. Crit Care Med 1997;25:620-8.

22. Wittmer VL, Simoes GM, Sogame LC, Vasquez EC. Effects of continuous positive airway pressure on pulmonary function and exercise tolerance in patients with congestive heart failure. Chest 2006;130:157-63.

23. Bellani G, Laffey JG, Pham T, Madotto F, Fan E, Brochard L, et al. Noninvasive ventilation of patients with acute respiratory distress syndrome. Insights from the LUNG SAFE Study. Am J Respir Crit Care Med 2017;195:67-77.

24. Mehta S, Hill NS. Noninvasive ventilation. Am J Respir Crit Care Med 2001;163:540-77.

25. Wood KA, Lewis L, Von Harz B, Kollef MH. The use of noninvasive positive pressure ventilation in the emergency department: Results of a randomized clinical trial. Chest 1998;113:1339-46.

26. Nava S, Hill N. Non-invasive ventilation in acute respiratory failure. Lancet 2009;374:250-9.

27. Nicholl J, West J, Goodacre S, Turner J. The relationship between distance to hospital and patient mortality in emergencies: An observational study. Emerg Med J 2007;24:665-8.

28. Pandor A, Thokala P, Goodacre S, Poku E, Stevens JW, Ren S, et al. Pre-hospital non-invasive ventilation for acute respiratory failure: A systematic review and cost-effectiveness evaluation. Health Technol Assess 2015;19:v-vi, 1-102. 
AlAhmari and Sreedharan: NIV and pre-hospital setting

29. Hubble MW, Richards ME, Wilfong DA. Estimates of cost-effectiveness of prehospital continuous positive airway pressure in the management of acute pulmonary edema. Prehosp Emerg Care 2008;12:277-85.

30. Garuti G, Bandiera G, Cattaruzza MS, Gelati L, Osborn JF, Toscani S, et al. Out-of-hospital helmet CPAP in acute respiratory failure reduces mortality: A study led by nurses. Monaldi Arch Chest Dis 2010;73:145-51.

31. AlAhmari M, Esquinas AM. Early failure of noninvasive ventilation in COPD: All cornerstones under surveillance? Intern Emerg Med 2016;11:617-8.

32. Waydhas C. Intrahospital transport of critically ill patients. Crit Care 1999;3:R83-9.

33. Papson JP, Russell KL, Taylor DM. Unexpected events during the intrahospital transport of critically ill patients. Acad Emerg Med 2007; 14:574-7.

34. Fanara B, Manzon C, Barbot O, Desmettre T, Capellier G. Recommendations for the intra-hospital transport of critically ill patients. Crit Care 2010;14:R87.

35. Brusasco C, Corradi F, De Ferrari A, Ball L, Kacmarek RM, Pelosi P. CPAP devices for emergency prehospital use: A bench study. Respir Care 2015;60:1777-85.

36. Volsko TA. Devices used for CPAP delivery. Respir Care 2019;64:723-34.

37. L'Her E, Roy A, Marjanovic N. Bench-test comparison of 26 emergency and transport ventilators. Crit Care 2014;18:506.

38. Scala R, Naldi M. Ventilators for noninvasive ventilation to treat acute respiratory failure. Respir Care 2008;53:1054-80.

39. Bello G, Ionescu Maddalena A, Giammatteo V, Antonelli M. Noninvasive options. Crit Care Clin 2018;34:395-412.

40. Brill AK. How to avoid interface problems in acute noninvasive ventilation. Breath 2014;10:231-42.

41. Milliner BH, Bentley S, DuCanto J. A pilot study of improvised CPAP (iCPAP) via face mask for the treatment of adult respiratory distress in low-resource settings. Int J Emerg Med 2019;12:7.

42. Mal S, McLeod S, Iansavichene A, Dukelow A, Lewell M. Effect of out-of-hospital noninvasive positive-pressure support ventilation in adult patients with severe respiratory distress: A systematic review and meta-analysis. Ann Emerg Med 2014;63:600-70.

43. Simpson PM, Bendall JC. Prehospital non-invasive ventilation for acute cardiogenic pulmonary oedema: An evidence-based review. Emerg Med J 2011;28:609-12.

44. Hensel M, Strunden MS, Tank S, Gagelmann N, Wirtz S, Kerner T. Prehospital non-invasive ventilation in acute respiratory failure is justified even if the distance to hospital is short. Am J Emerg Med 2019;37:651-6.

45. Elliott MW, Confalonieri M, Nava S. Where to perform noninvasive ventilation? Eur Respir J 2002;19:1159-66.

46. Norwegian Institute of Public Health. Effect of interventions for Implementing Clinical Practice Guidelines, Oslo. 2015. Available from: https://www.fhi.no/en/publ/2015/effect-of-interventions-for-implement ing-clinical-practice-guidelines/. [Last accessed on 2019 Nov 05].

47. Carlucci A, Delmastro M, Rubini F, Fracchia C, Nava S. Changes in the practice of non-invasive ventilation in treating COPD patients over 8 years. Intensive Care Med 2003;29:419-25.

48. Warren J, Fromm RE Jr., Orr RA, Rotello LC, Horst HM; American College of Critical Care Medicine. Guidelines for the inter - And intrahospital transport of critically ill patients. Crit Care Med 2004;32:256-62.

49. British Thoracic Society Standards of Care Committee. Non-invasive ventilation in acute respiratory failure. Thorax 2002;57:192-211.

50. Lopez-Campos JL, Garcia Polo C, Leon Jimenez A, Arnedillo A, Gonzalez-Moya E, Fenandez Berni JJ. Staff training influence on non-invasive ventilation outcome for acute hypercapnic respiratory failure. Monaldi Arch Chest Dis 2006;65:145-51. 